\title{
EFFICACY OF QUERCETIN ON ALVEOLAR BONE STRUCTURE OF RATS WITH INDUCED DIABETES
}

\author{
Mariam A. Abu Ayana ${ }^{\prime} B D S$, Nawal A. Elmasry'PhD, Fathy I. Shehata ${ }^{2} P h D$, Nesma M. Khalil ${ }^{3} P h D$
}

\begin{abstract}
INTRODUCTION: Diabetic osteopenia is the sixth classic complication of Diabetes mellitus. High glucose level is capable of triggering increased oxidative stress which induce osteoblast apoptosis. Quercetin, a powerful natural antioxidant, can protect many organs against oxidative damage, including bone.

OBJECTIVES: The present study is designed to investigate the effect of quercetin administration on the alveolar bone in rats with induced diabetes. MATERIALS AND METHODS: Twenty-four adult male rats were divided into three equal groups (8 rats each) as follows: Group I: Control group, Group II: diabetic group (with no treatment), Group III: quercetin treated group (induction of diabetes with oral administration of quercetin dose $100 \mathrm{mg} / \mathrm{kg} /$ day for 12 weeks). Diabetes was induced in group II and group III by a single intraperitoneal injection of Streptozotocin (STZ). After 12 weeks all rats were sacrificed and the mandibles were dissected out and prepared for histological analysis using scanning electron microscope (SEM), and energy dispersive x-ray microanalysis (EDX).

RESULTS: In diabetic group, there was significant increase in blood sugar level. Bone surface revealed irregular surface with multiple resorptive pits. Moreover, there was significant decrease in calcium level and increase in phosphorous level while in quercetin group. Both blood sugar level and alveolar bone surface relatively returned back to normal. Also there was slight decrease in calcium and increase in phosphorous in comparison to control group.
\end{abstract}

CONCLUSIONS: Quercetin exerts protective effects on STZ-induced oxidative stress in diabetic rats restoring the architecture of bone. KEYWORDS: Quercetin, Streptozotocin, Diabetes, Alveolar bone.

1- Demonstrator of oral biology, Faculty of dentistry, Alexandria University.

2- Professor of oral biology, Faculty of Dentistry, Alexandria University.

3- Lecturer of oral biology, Faculty of Dentistry, Alexandria University.

\section{INTRODUCTION}

Quercetin (3, 5, 7- pentahydroxyflavone ) is a powerful natural antioxidant (1). It is a naturally occurring flavonoid, which is widely distributed in the plant kingdom. It is widespread in a variety of foods including onions, apples, grapes, berries and some vegetables as well as many seeds, nuts, flowers, barks and leaves (2).

It has been demonstrated that quercetin can protect many types of tissue or organs against oxidative damage, including liver, kidney and pancreatic gland (3). It has been reported that quercetin exerts protective effects against $\beta$ cell damage in diabetes and is capable of decreasing serum glucose level in diabetic rats (4).

Oxidative stress is described as an imbalance between an overproduction of reactive oxygen species (ROS) and an insufficient defense of antioxidants (5). It is caused by an increase in intracellular reactive oxygen species (ROS), plays a central role in insulin resistance and in pancreatic $\beta$ cell death during the progressive deterioration in glucose tolerance and development of diabetes. Increased oxidative stress produces serious oxidative damage in the brain under diabetic conditions that affects all of the cellular components, including proteins, lipids and nucleic acids (6).

Quercetin (QE) was shown to induce a dose-dependent decrease in plasma glucose levels, in addition to regenerating pancreatic islets, preserving the integrity of pancreatic $\beta$-cells and normalizing glucose tolerance tests. It has been shown in streptozotocin-induced diabetic rats to reduce oxidative stress markers (plasma thiobarbituric acid reactive substances and hydroperoxides) and regulate the detoxifying enzymes, superoxide dismutase and catalase (7). It has been also recently revealed that it alleviates diabetic symptoms and reduces the disturbance of hepatic gene expression in streptozotocininduced diabetic mice (8).

It has been proved that $\mathrm{QE}$ reduces bone resorption in vitro which is one of the complications of diabetes mellitus via the direct targeting of the mature osteoclasts by a mechanism involving estrogen receptors (ERs). It has been shown that estrogen enhances osteoblast differentiation and bone formation and the conditioned medium of estrogentreated osteoblast cultures inhibits osteoclast development. Many special properties of quercetin make it an ideal candidate substance for the prevention and treatment of diabetic osteopenia (9).

Diabetes mellitus (DM) is a major clinical and public health problem (10). It is a chronic systemic metabolic disorder. DM is characterized by hyperglycemia due to a deficiency of insulin secretion caused by pancreatic $\beta$-cell dysfunction and/ or insulin resistance (10). Increase incidence of morbidity and mortality has been associated with diabetes as its long-term complications affect many important organs. Diabetic complications can be classified as microvascular and macrovascular complications. Other important clinical complications include delayed wound healing, periodontal disease and alveolar bone loss (11).

A variety of bone-related changes are known to be influenced by hyperglycemia such as bone mineral density, geometry, microarchitecture (trabecular, cortical thickness, and bone area), and biomechanical markers of bone turnover (ultimate strain, strength and load, and stiffness $(12,13)$. In addition, formation of the collagen network is affected by an increase in matrix metalloproteinase (MMP) expression in diabetic conditions, especially for MMP-9, which is considered a diabetogenic factor and is upregulated in Type1DM, contributing to collagen degradation and resulting in low bone collagen content and poor bone biomechanical integrity (14).

Alveolar bone is a specialized part of the mandibular and maxillary bone that form the primary support structure for the teeth. It is the least stable of the periodontal tissue, because it is subjected to continuous modeling and 
remodeling associated with tooth eruption and functional requirements $(15)$.

Diabetic osteopenia is one of the most serious complications of DM which may lead to increase incidence of bone fracture. High glucose level is capable of influencing osteoblast differentiation, impairing bone formation and inhibiting bone mineralization (16). Diabetes has been implicated in the progression of periodontal disease. It causes a more persistent inflammatory response, greater loss of attachment and more alveolar bone resorption, and impaired new bone formation (17).

In addition, hyperglycemia is able to trigger increased oxidative stress that inhibit osteoblast differentiation and induce osteoblast insults and apoptosis, and has been deemed as an important contributing factor for the incidence of diabetic osteopenia. Therefore, simultaneous control of hyperglycemia and oxidative stress has great potential in controlling the incidence and development of diabetic osteopenia (18).

\section{MATERIALS AND METHODS}

The study design was approved by the Institutional Ethical Committee of the Faculty of Dentistry Alexandria University

Twenty-four adult male rats weighing 200-250 grams (approximately six months of age) were used in this study. These animals were obtained from and caged in the Institute of Medical Research, Alexandria University. They were caged in specially designed wire mesh cages. The animals were supplied a regular diet throughout the whole experimental period which lasted for 12 weeks.

The animals were divided into three equal groups ( 8 rats each) as follows:

Group I: Control group.

Group II: Diabetic group (with no treatment).

Group III: Quercetin treated group (after induction of diabetes quercetin was administrated orally at a dose of $100 \mathrm{mg} / \mathrm{kg} /$ day for 12 weeks) (19).

For group I (control), the rats were injected with vehicle (saline) to control the influence of any injection stress or buffer-induced effects on the animals.

\section{Induction of diabetes}

For groups II, III the rats were fasted overnight and diabetes was induced by a single intraperitoneal injection of Streptozotocin $40 \mathrm{mg} / \mathrm{kg}$ body weight in $0.1 \mathrm{M}$ citrate buffer (20).

\section{Administration of Quercetin}

Quercetin which was used in the experiment was purchased from Sigma -Aldrich Chemical Company. It was available in powder form and it was dissolved in distilled water and administrated orally by oral gavage syringe.

At the end of 12 weeks, all rats were sacrificed. The mandible of each rat was dissected out. The right molar segments were prepared for Scanning Electron Microscope (SEM) and Energy Dispersive X-ray microanalysis (EDX).

\section{Measurement of Blood Glucose Level}

Blood glucose level of the animals in group I, II and III was measured 48 hours after the administration of Streptozotocin then every week throughout the time of experiment. Blood sample was obtained from the tail vein of the animals and their blood glucose level was determined in $\mathrm{mg} / \mathrm{dl}$ using a digital glucometer (20).

\section{Scanning Electron Microscope (SEM) (21)}

Specimens were fixed in $2.5 \%$ glutaraldehyde in phosphate buffer (PH 7.3) for 48 hours and rinsed in phosphate buffer for 10 minutes then dehydrated in ascending grades of ethanol solution $50 \%, 70 \%, 90 \%$, and exchanges of $100 \%$.

These specimens were exposed to critical point drying. Then they were air-dried in a vacuum desiccator in which air was evacuated. After which the specimen was mounted on aluminum SEM stubs for gold sputtering. This was achieved by the deposition of an evaporated thin layer of gold over the samples. After coating, the samples were ready for scanning electron microscopic examination.

\section{Energy Dispersive X-ray (EDX) (21)}

The specimens were washed under running water, dehydrated and air-dried. The surfaces of the mandibles of the study and control groups were exposed to x-ray analysis using EDX system to analyze the different percentages of calcium and phosphorus.

\section{STATISTICAL ANALYSIS}

Results of the blood glucose level and EDX microanalysis were collected and analyzed using ANOVA test to reveal the difference in the level of calcium and phosphorus and blood glucose level between the three groups.

\section{RESULTS}

\section{Blood glucose level}

The initial and final blood sugar levels in the different groups are summarized by mean and standard deviation in table (1). There was a statistically significant increase in final blood sugar level in diabetic group (II) in relation to control group (I) $(\mathrm{P} 1<0.01)$. In quercetin treated group (III), the mean final blood sugar level decreased to values close to control group(I) $(\mathrm{P} 2=0.98)$, moreover, the difference in the final blood sugar level between both diabetic group (II) and quercetin treated group (III) was statistically significant $(\mathrm{P} 3<0.01)$.

Table 1: Comparison between the three studied groups regarding the level of blood glucose.

\begin{tabular}{|c|c|c|c|c|c|c|c|}
\hline & $\begin{array}{l}\text { Control } \\
\text { group }\end{array}$ & $\begin{array}{l}\text { Diabetic } \\
\text { group }\end{array}$ & $\begin{array}{l}\text { Quercetin } \\
\text { treated group }\end{array}$ & $\begin{array}{l}\mathbf{F} \\
\mathbf{P}\end{array}$ & P1 & P2 & P3 \\
\hline $\begin{array}{l}\text { Initial } \\
\text { blood } \\
\text { glucose } \\
\text { Range } \\
\text { Mean } \pm S \\
\text {.D. } \\
\end{array}$ & $\begin{array}{l}95-114 \\
107.6 \pm 5 . \\
76\end{array}$ & $\begin{array}{l}231-410 \\
283.88 \pm 5 \\
8.26\end{array}$ & $\begin{array}{l}231-450 \\
301.88 \pm 66.33\end{array}$ & $\begin{array}{l}10.2 \\
0.00 \\
1 *\end{array}$ & $\begin{array}{l}0.00 \\
1 *\end{array}$ & $\begin{array}{l}0.00 \\
1 *\end{array}$ & 0.365 \\
\hline 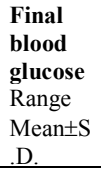 & $\begin{array}{l}105-118 \\
112.13 \pm \\
4.19\end{array}$ & $\begin{array}{l}295-347 \\
312.75 \pm 1 \\
5.04 \\
\end{array}$ & $\begin{array}{l}97-127 \\
108.50 \pm 11.33\end{array}$ & $\begin{array}{l}10.5 \\
0.00 \\
1 *\end{array}$ & $\begin{array}{l}0.00 \\
1 * \\
\end{array}$ & 0.98 & $0.001 *$ \\
\hline P4 & 0.168 & 0.106 & $0.001^{*}$ & & & & \\
\hline
\end{tabular}

\section{Scanning electron microscopic results Group 1 (control group)}

The surfaces of the buccal cortical plates of the alveolar bone showed a generalized pattern of smooth and uniform surface topography with regularly outlined and well defined nutritive canals (Fig.1). 


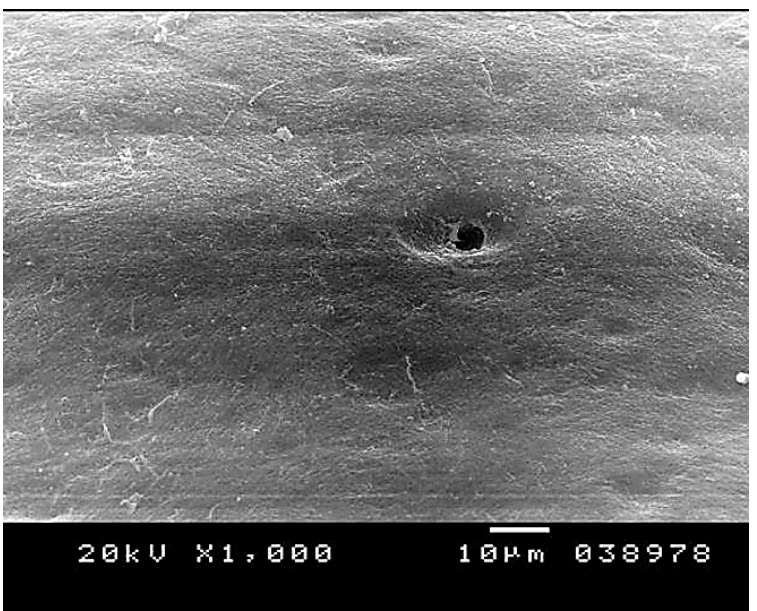

Figure 1: Scanning electron microscope SEM \{Control group\} of buccal cortical plate showing smooth bone surface prevailing in most of the figure width with regularly outlined nutritive canal. (x1000)

\section{Group 2 (Diabetic group) untreated group}

The surfaces exhibited a generalized roughening and porosity with irregularly outlined nutritive canals (Fig. 2), and associated with some smooth and regular areas (Fig. 3)

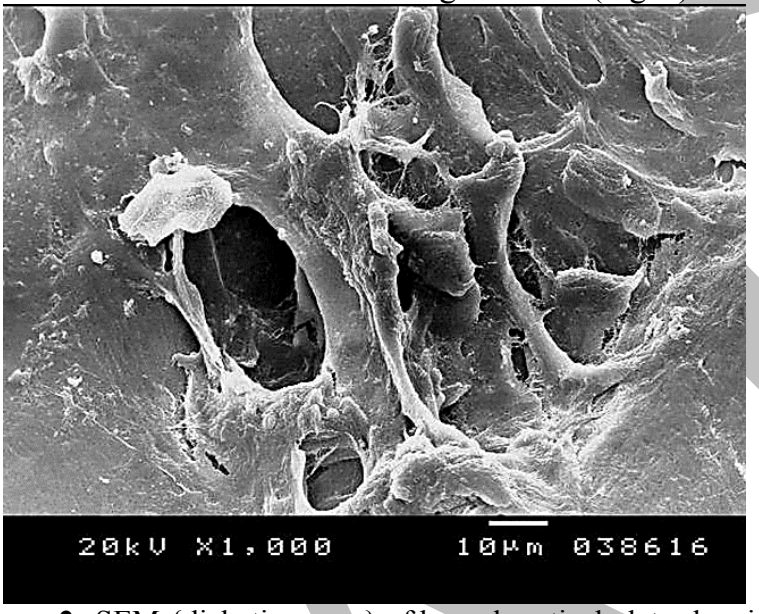

Figure 2: SEM \{diabetic group\} of buccal cortical plate showing generalized severe roughened bone surface with irregularly outlined nutritive canal. (x1000).

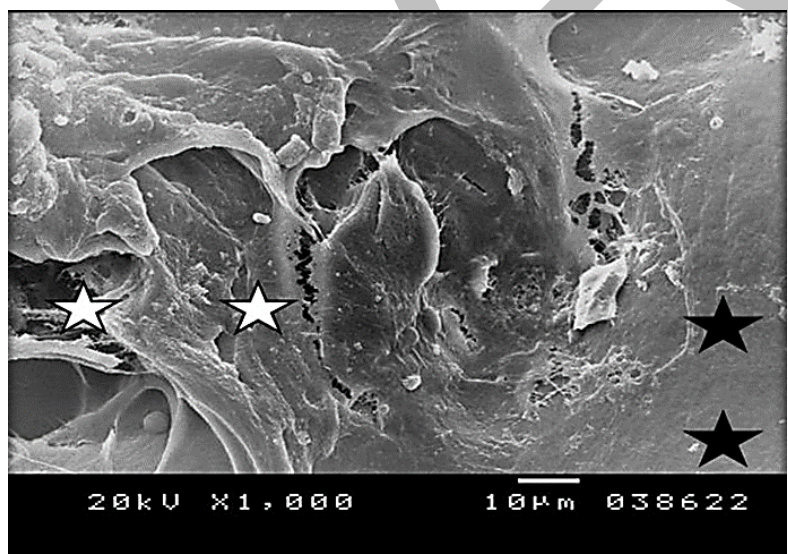

Figure 3: SEM \{diabetic group \} of buccal cortical plate showing alternating areas of smooth bone surface (black asterisks) and areas of resorption with severe roughness and irregular bone surface (white asterisks) (x1000).

\section{Group 3 (Quercetin treated diabetic group)}

The bone surfaces exhibited a marked masking of the diabetic changes which were seen in association with diabetic group.
The positive changes included decrease in surface roughness and increase in smooth surface areas (Fig. 4). The repair was noted in all areas examined all over the cortical plates. Slight irregularities were observed at the interior surface of the nutritive canal (Fig. 5).

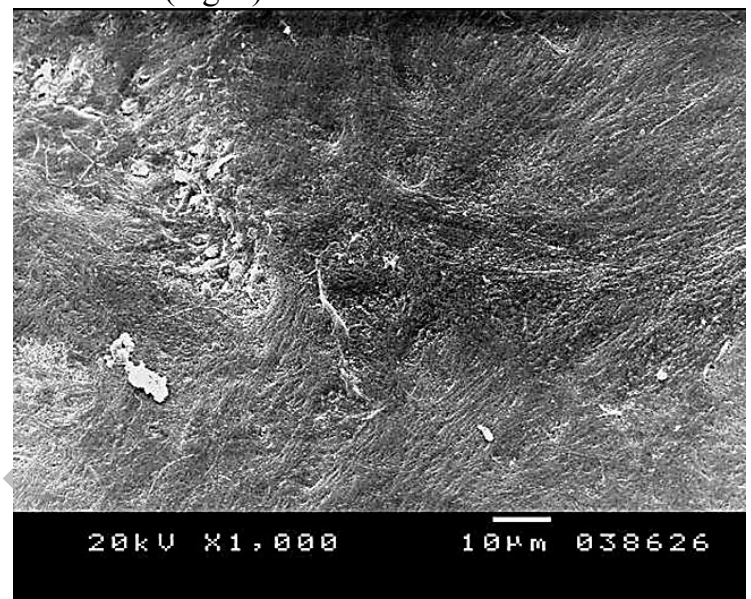

Figure 4: SEM \{Quercetin treated group $\}$ of buccal cortical plate showing moderate smooth surface topography (x1000).

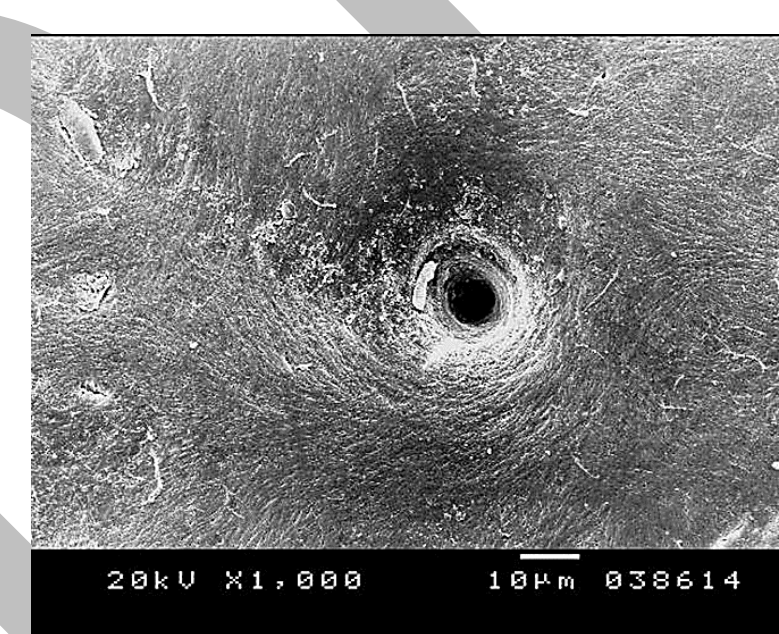

Figure 5: SEM \{Quercetin treated group of buccal cortical plate showing smooth bone surface prevailing in most of the figure width containing nutritive canal with mild roughness around nutritive canal. (x1000).

\section{Energy dispersive x-ray analysis (EDX)}

The calcium and phosphorous levels in different groups are summarized in table (2). There was statistically significant decrease in calcium level and increase in phosphorous level in diabetic group (II) in relation to control group (P1 for calcium $=0.013)$ and $(\mathrm{P} 1$ for phosphorous $=0.001)$. In quercetin treated group (III), there was a slight decrease in calcium level and increase in phosphorous level but the values of calcium and phosphorous were closer to control group than that of diabetic group ( $\mathrm{P} 2$ for calcium $=0.033$ ) and ( $\mathrm{P} 2$ for phosphorous $=0.016)$. Moreover, the difference in calcium and phosphorous levels between quercetin and diabetic groups were statistically significant (P3 for calcium $=0.019)$ and $(\mathrm{P} 3$ for phosphorous $=0.022)$.

\section{DISCUSSION}

Quercetin is one of the best known bioflavonoid; bioflavonoids comprise numerous natural compounds, such as catechin, quercetin and rutin. Quercetin is abundant in a variety of fruits and vegetables (22). Administration of quercetin partially prevents degranulation and degeneration of $\beta$-cell, and significantly lowers the serum glucose levels. 
In addition, the lipid peroxidation in pancreatic tissue, serum nitric oxide production becomes significantly lowered, and the activities of serum antioxidants become significantly increased by quercetin, indicating that the protective effect of quercetin on $\beta$-cell is attributable to its antioxidant nature which in turn reduces bone resorption which is one of the complications of diabetes mellites (23).

Table 2: Comparison between different studied groups regarding Calcium and phosphorus level.

\begin{tabular}{|c|c|c|c|}
\hline & Control gp & Diabetic gp & $\begin{array}{l}\text { Quercetin } \\
\text { treated gp }\end{array}$ \\
\hline $\begin{array}{l}\text { Calcium level } \\
\text { Range } \\
\text { Mean } \pm \text { S.D. }\end{array}$ & $\begin{array}{c}65-69 \\
67.16 \pm 1.40\end{array}$ & $\begin{array}{c}39.8-45 \\
42.68 \pm 1.79\end{array}$ & $\begin{array}{l}56.8-61.5 \\
58.86 \pm 1.50\end{array}$ \\
\hline $\begin{array}{l}\text { ANOVA test } \\
\text { P }\end{array}$ & & $\begin{array}{c}8.98 \\
0.011 *\end{array}$ & \\
\hline P1 & & $0.013 *$ & \\
\hline P2 & & & $0.033^{*}$ \\
\hline P3 & & & $0.019^{*}$ \\
\hline $\begin{array}{l}\text { Phosphorus } \\
\text { level } \\
\text { Range } \\
\text { Mean } \pm \text { S.D. }\end{array}$ & $\begin{array}{c}31-35 \\
32.84 \pm 1.40\end{array}$ & $\begin{array}{c}55-65.7 \\
58.58 \pm 3.32\end{array}$ & $\begin{array}{l}38.5-43.2 \\
41.14 \pm 1.50\end{array}$ \\
\hline $\begin{array}{l}\text { ANOVA test } \\
\text { P }\end{array}$ & & $\begin{array}{c}12.65 \\
0.003 *\end{array}$ & \\
\hline P1 & & $0.001 *$ & \\
\hline P2 & & & $0.016^{*}$ \\
\hline P3 & & & $0.022 *$ \\
\hline
\end{tabular}

ANOVA test was done to compare between the three groups followed by post hoc test to determine the significant between each two groups P1 comparison between control and diabetic groups. P2 comparison between control and treated groups.

P3 comparison between diabetic and treated groups.

The present study evaluated the effect of quercetin, when administrated orally on the alveolar bone loss induced by diabetes. This was done by SEM and EDX. It evaluated as well its effect on hyperglycemia in a diabetic rat model.

Induction of diabetes mellitus in laboratory animals was done by several methods with many difficulties and variable success. Dave V et al., (24) removed surgically the pancreas and it was an effective method; however, to induce diabetes at least $90 \%$ of the pancreas had to be removed. A variety of Type1 diabetic rodent models have been pharmacologically induced by compounds such as Alloxan, Streptozotocin (STZ),Vacor, Dithizone and 8hydroxyquinon (25).

Akbarzadeh A et al., (26) used streptozotocin to create experimental diabetes because it is simple, effective and convenient method. In rats a single dose of streptozotocin is capable for inducing diabetes (27). One of the actions which has been attributed to STZ is depletion of intracellular nicotineamide dinucleotide (NAD) in islet cells. In addition, STZ has been shown to induce DNA strand breaks and methylation in pancreatic islet cells. STZ enters pancreatic beta $(\beta)$ cells through glucose transporter 2 (GLUT2) in the plasma membrane leading to cellular toxicity and local immune responses that lead to hypoinsulinemia and hyperglycemia in animals.Ninety days period was estimated for this experiment. This period has been shown to be enough to induce diabetes complications in bone (28).

Bortolin RH et al., (29) results demonstrated significant bone loss associated with long-term T1DM. That study was based on protection against T1DM-Induced Bone Loss by Zinc Supplementation.

In the current study, blood glucose levels were measured at regular intervals throughout the experimental period. The increase of blood glucose levels was statistically significant in the diabetic group after using streptozotocin as diabetes inducer which caused toxicity of the beta cells of the pancreas leading to emergence of clinical diabetes in 2-4 days. STZ penetrates the pancreas increasing oxidative stress resulting in destruction of beta cells (30). The hyperglycemic state was almost stable in the diabetic group throughout the experimental time.

A study done in 2013 by El-Amin M et al., (31) has revealed that hyperglycemia, hypoinsulinemia, polyphagia, polyuria and polydipsia accompanied by weight loss were seen in adult rats within three days of streptozotocin treatment and within one week to ten days, the amount of relevant factors were almost stable, which indicated irreversible destruction of the Langerhans islets cells. However, for treated group, after the start of oral quercetin administration, the mean blood glucose level showed significant improvement. Abdelmoaty MA et al., (32) suggested that QE supplementation has proven to be beneficial in decreasing blood glucose concentration, promoting regeneration of the pancreatic islets and increasing insulin release in STZ-induced diabetic rats; thus exerting its beneficial antidiabetic effects.

The scanning electron micrographs (SEM) of the diabetic group revealed an irregular, resorbed surface of the outer cortical plate of bone indicating the progressive bone resorption associated with diabetes. This result is supported by Wongdee $\mathrm{K}$ et al., (33)who ensured that there is great association between diabetes and osteoporosis. Another study done by Labanca $M$ et al., (34) proved that increased osteoclastic activity in cases of osteoporosis resulted in bone resorption which took the upper hand than bone formation.

Our elemental microanalysis (EDX) revealed a decrease in calcium concentration in relation to phosphorous in the diabetic animals. The results of the elemental microanalysis coincided with scanning electron microscopic results. Negareddy et al. (35) mentioned that energy dispersive x-ray analysis is considered an efficient method to detect different percentages of minerals in the bone, also allows for region specific analysis of elemental composition and it is better than such analysis which only provide information about total bone composition. It has been proven that diabetes resulted in abnormalities in calcium and phosphorous metabolism leading to increased serum calcium concentration which resulted from the release of calcium from bone tissues.

Berezin AE reported controversial alterations in the RANK/RANKL/OPG (receptor activator of nuclear factor kappa $\beta$ ligand/osteoprotegerin) system in hyperglycemic conditions. An increase in RANKL mRNA expression in diabetic bone has been shown while a decrease in OPG gene expression was also observed in T1DM patients. When RANKL expression increases relative to OPG, RANKL becomes available to bind RANK on osteoclast precursors, tipping the balance to favor activation of osteoclast formation and bone resorption (36).

On the other hand, the administration of quercetin in the present study, prevented alveolar bone loss and restored its normal original architecture. SEM results of quercetin group revealed a relatively smooth bone surface indicating quercetin effect on bone formation and thus preventing severe bone resorption as a complication of diabetes.

The results of EDX revealed increase of the calcium level and the relative regaining of the normal ratio between calcium and phosphorous in the quercetin group when compared to diabetes group. Appropriate balance of calcium and 
phosphorous levels is a key for maintaining healthy bone and both minerals are critical to support bone formation (37).

A study done in 2011 by Wei Liang et al., (23) revealed alterations occuring both trabecular bone and cortical bone in diabetic rats by Micro- CT scanning analysis, which might contribute to the deteriorative biomechanical performance of femur under diabetic condition. Quercetin significantly improved the trabecular bone mass loss and microarchitecture deterioration in diabetic rats with less resorptive pits and smoother bone surface compared to diabetic group. It also showed significant improvement of bone mineral content and increasing in calcium level in quercetin group in comparison to the diabetic group.

A study done in 2008 by Wong RW et al., (38) demonstrated that quercetin when used with collagen matrix significantly increased new bone formation locally when grafted into skull defects. It is one of the most potent osteogenic chemicals ever discovered. It reduces bone resorption via a mechanism involving estrogen receptors (ERs) expressed by osteoblasts. It has been shown that estrogen inhibits osteoclast development. Thus, estrogen is one of the most important sex steroids for the maintenance of bone balance. It has been reported that quercetin interact with estrogen receptors (ERa and $\mathrm{ERb}$ ) present within the osteoblasts, which facilitate upregulation of gene expression and proliferation of cells, boost the bone cells' metabolic activity and also stimulate the formation of bone by enhancing osteoblast differentiation (39).

Wei Liang et al., found that oral administration of quercetin was capable of reversing the decreased serum osteocalcin and serum alkaline phosphatase (ALP) activity which were found in diabetic rats and therefore enhanced bone mineralization (23).

All of the previous SEM and EDX findings of the deteriorated bone tissue of diabetic group, showed remarkable differences from those of quercetin and control groups. The observed histological findings of the present study assured the positive influence of quercetin administration on the restoration of the structure of the alveolar bone.

\section{CONCLUSIONS}

Quercetin exerts protective effects on alveolar bone structure affected by diabetes in rats. The efficacy of quercetin therapy in diabetes mellitus could be attributed to the hypoglycemic state and its osteogenic effect.

\section{CONFLICT OF INTEREST}

We declare that we have no conflicts of interest.

\section{REFERENCES}

1. Yokoyama A, Yokoyama A, Sakakibara H, Yokoyama A, Sakakibara H, Crozier A, et al. Quercetin metabolites and protection against peroxynitrite-induced oxidative hepatic injury in rats. Free Radic Res. 2009;43:913-21.

2. Seiva FR, Chuffa LGA, Braga CP, Amorim JPA, Fernandes AAH. Quercetin ameliorates glucose and lipid metabolism and improves antioxidant status in postnatally monosodium glutamate-induced metabolic alterations. Food Chem Toxicol. 2012;50:3556-61.

3. Lai F, Franceschini I, Corrias F, Sala MC, Cilurzo F, Sinico $\mathrm{C}$, et al. Maltodextrin fast dissolving films for quercetin nanocrystal delivery. A feasibility study. Carbohydr Polym. 2015;121:217-23.
4. Welch A, MacGregor A, Jennings A, Fairweather-Tait S, Spector T, Cassidy A. Habitual flavonoid intakes are positively associated with bone mineral density in women. J Bone Miner Res. 2012;27:1872-8.

5. Huang Q, Gao B, Jie Q, Wei BY, Fan J, Zhang HY, et al. Ginsenoside- $\mathrm{Rb} 2$ displays anti-osteoporosis effects through reducing oxidative damage and bone-resorbing cytokines during osteogenesis. Bone. 2014;66:306-14.

6. Youl E, Bardy G, Magous R, Cros G, Sejalon F, Virsolvy A, et al. Quercetin potentiates insulin secretion and protects INS-1 pancreatic $\beta$-cells against oxidative damage via the ERK1/2 pathway. Br J Pharmacol. 2010;161:799-814

7. Khaki A, Fathiazad F, Nouri M, Khaki A, Maleki NA, Khamnei HJ, et al. Beneficial effects of quercetin on sperm parameters in streptozotocin-induced diabetic male rats. Phytother Res. 2010;24:1285-91.

8. Kobori M, Masumoto S, Akimoto Y, Takahashi Y. Dietary quercetin alleviates diabetic symptoms and reduces streptozotocin-induced disturbance of hepatic gene expression in mice. Mol Nutr Food Res. 2009;53:859-68.

9. Derakhshanian H, Ghadbeigi S, Rezaian M, Bahremand A, Javanbakht $\mathrm{MH}$, Golpaie A, et al. Quercetin improves bone strength in experimental biliary cirrhosis. Hepatol Res. 2013;43:394-400.

10. Albert DA, Ward A, Allweiss P, Graves DT, Knowler WC, Kunzel C, et al. Diabetes and oral disease: implications for health professionals. Ann N Y Acad Sci. 2012;1255:1-15.

11. Fagot-Campagna A, Bourdel-Marchasson I, Simon D. Burden of diabetes in an aging population: prevalence, incidence, mortality, characteristics and quality of care. Diabetes Metab. 2005;31:5S35-52.

12. Gupta S, Mukherjee M. Diabetes mellitus and its treatment with some traditional herbs from the different districts of West Bengal: A Review. Int $\mathrm{J}$ PharmTech Res. 2014;6:1941-9.

13. Unnanuntana A, Rebolledo BJ, Khair MM, DiCarlo EF, Lane JM. Diseases affecting bone quality: beyond osteoporosis. Clin Orthop Relat Res. 2011;469:2194-206.

14. Koh WP, Wang R, Ang LW, Heng D, Yuan JM, Mimi CY. Diabetes and risk of hip fracture in the Singapore Chinese Health Study. Diabetes Care. 2010;33:1766-70.

15. Sodek J, Mckee MD. Molecular and cellular biology of alveolar bone. Periodontol 2000. 2000;24:99-126.

16. Zhen D, Chen Y, Tang X. Metformin reverses the deleterious effects of high glucose on osteoblast function. J Diabetes Complications. 2010;24:334-44.

17. Silva J, Lorencini M, Peroni L, De La Hoz C, Carvalho H, Stach-Machado D. The influence of type I diabetes mellitus on the expression and activity of gelatinases (matrix metalloproteinases-2 and -9) in induced periodontal disease. J Periodontal Res. 2008;43: 48-54.

18. Hamada Y, Fujii H, Fukagawa M. Role of oxidative stress in diabetic bone disorder. Bone. 2009;45:S35-8.

19. Mahmoud MF, Hassan NA, El Bassossy HM, Fahmy A. Quercetin protects against Diabetes-Induced Exaggerated Vasoconstriction in Rats: Effect on Low Grade Inflammation. PLoS One. 2013;8:e63784.

20. Ibuki FK, Simões A, Nogueira FN. Antioxidant enzymatic defense in salivary glands of streptozotocin-induced diabetic rats: a temporal study. Cell Biochem Funct. 2010;28:503-8.

21. Goldstein J, Newdury D, Joy D, Lyman C, Echlin P. Scanning electron microscope and X-ray analysis. $3^{\text {rd }}$ ed. New York: Kluwer Academic/ Plenum publishers; 2003. 
22. Zhou Y, Wu Y, Jiang X, Zhang X, Xia L, Lin K, et al. The effect of quercetin on the osteogenesic differentiation and angiogenic factor expression of bone marrow-derived mesenchymal stem cells. PloS One. 2015;10:e0129605.

23. Liang W, Luo Z, Ge S, Li M, Du J, Yang M, et al. Oral administration of quercetin inhibits bone loss in rat model of diabetic osteopenia. Eur J Pharmacol. 2011;670:317-24.

24. Dave V, Sharma R, Sharma S, Jain P, Yadav S. Experimental models on diabetes: a comprehensive review. IJAPR. 2013;4:1-8.

25. Hayashi K, Kojima R, Ito M. Strain differences in the diabetogenic activity of streptozotocin in mice. Biol Pharm Bull. 2006;29:1110-9.

26. Akbarzadeh A, Norouzian D, Mehrabi M, Jamshidi S, Farhangi A, Verdi AA, et al. Induction of diabetes by streptozotocin in rats. Indian J Clin Biochem. 2007;22:604.

27. Motyl K, McCabe LR. Streptozotocin, type I diabetes severity and bone. Biol Proced Online. 2009;11:296-315.

28. Szkudelski T. The mechanism of alloxan and streptozotocin action in B cells of the rat pancreas. Physiol Res. 2001;50:537-46.

29. Bortolin RH, Abreu BJdGA, Ururahy MAG, de Souza KSC, Bezerra JF, Loureiro MB, et al. Protection against T1DMinduced bone loss by zinc supplementation: biomechanical, histomorphometric, and molecular analyses in STZ-induced diabetic rats. PloS One. 2015;10:e0125349.

30. Coskun O, Kanter M, Korkmaz A, Oter S. Quercetin, a flavonoid antioxidant, prevents and protects streptozotocininduced oxidative stress and $\beta$-cell damage in rat pancreas. Pharmacol Res. 2005;51:117-23.

31. El-Amin M, Virk P, Elobeid M, Almarhoon ZM, Hassan ZK, Omer SA, et al. Anti-diabetic effect of Murraya koenigii (L) and Olea europaea (L) leaf extracts on streptozotocin induced diabetic rats. Pak J Pharm Sci. 2013;26:359-65.

32. Abdelmoaty MA, Ibrahim M, Ahmed N, Abdelaziz M. Confirmatory studies on the antioxidant and antidiabetic effect of quercetin in rats. Indian $\mathrm{J}$ Clin Biochem. 2010;25:188-92.

33. Wongdee K, Charoenphandhu N. Osteoporosis in diabetes mellitus: Possible cellular and molecular mechanisms. World J Diabetes. 2011;2:41-8.

34. Labanca M, Binello PB. Osteoporosis and Bone Defects in Dentistry: New Drugs and Treatment Options. Open Conf Proc J. 2010;1:33-8.

35. Nagareddy PR, Lakshmana M. Assessment of experimental osteoporosis using CT-scanning, quantitative X-ray analysis and impact test in calcium deficient ovariectomized rats. J Pharmacol Toxicol Methods. 2005;52:350-5.

36. Berezin AE. Single Sample and Serial Measurements of Osteoprotegerin Level as a Target of Therapy in Type 2 Diabetes Mellitus? BMGT. 2016;3:57-71.

37. Shapiro R, Heaney R. Co-dependence of calcium and phosphorus for growth and bone development under conditions of varying deficiency. Bone. 2003;32:532-40.

38. Wong RW, Rabie ABM. Effect of quercetin on bone formation. J Orthop Res. 2008;26:1061-6.

39. Gupta SK, Kumar R, Mishra NC. Influence of quercetin and nanohydroxyapatite modifications of decellularized goatlung scaffold for bone regeneration. Mater Sci Eng C Mater Biol Appl. 2017;71:919-28. 